\section{Congenital malformations in Rio de Janeiro, Brazil: prevalence and associated factors}

\author{
Malformações congênitas no Município do \\ Rio de Janeiro, Brasil: prevalência e fatores \\ associados a sua ocorrência
}

\author{
1 Escola Nacional de Saúde \\ Pública Sergio Arouca \\ Fundação Oswaldo Cruz, \\ Rio de Janeiro, Brasil. \\ 2 Centro de Vigilância \\ Epidemiológica, Secretaria \\ de Estado de Saúde \\ do Rio de Janeiro. \\ Rio de Janeiro, Brasil. \\ Correspondence \\ C. M. S. Costa \\ Programa de Assistência \\ Integral a Saúde da Mulher, \\ da Criança e do Adolescente, \\ Centro de Vigilância \\ Epidemiológica, \\ Secretaria de Estado de \\ Saúde do Rio de Janeiro. \\ Rua México 128, sala 415, \\ Rio de Janeiro, $R J$ \\ 20031-142, Brasil. \\ cms_costa@yahoo.com.br
}

\begin{abstract}
This study aims to estimate the prevalence of congenital malformations and their correlation with socioeconomic and maternal variables. The design was cross-sectional, based on a sample of 9,386 postpartum women after admission for childbirth in maternity hospitals in the city of Rio de Janeiro, Brazil. Data were collected through interviews with mothers in the immediate postpartum, as well as by consulting the patient records of both the mothers and newborn infants. Prevalence of congenital malformations at birth was 1.7\%, and minor malformations were the most frequent. Neural tube defects were the most frequent major malformations. According to multivariate analysis, congenital malformations were statistically associated with: maternity hospitals belonging to or outsourced by the Unified National Health System (SUS) and inadequate prenatal care $(\leq 3$ visits). This study highlights the importance of measures for health promotion and disease prevention in childbearing-age women, with special attention to prenatal care and childbirth, which can directly influence neonatal indicators and prevention of birth defects.
\end{abstract}

Congenital Defects; Newborn; Prevalence; Risk Factors
Cláudia Maria da Silva Costa 1,2

Silvana Granado Nogueira da Gama ${ }^{1}$

Maria do Carmo Leal 1

\section{Introduction}

With the decrease in the infant mortality rate, congenital malformations have gained greater visibility and are currently the second cause of infant mortality, accounting for $15 \%$ of infant deaths ( $<1$ year) in the city of Rio de Janeiro in 2000 and $18 \%$ in 20031 . To the extent that infectious diseases and nutritional deficiency have been controlled, perinatal causes and congenital malformations have been highlighted in public health, demanding specific measures to prevent them and control their sequelae.

Population-based studies on malformations are rare in Brazil and have been limited to hospital data such as those comprising the ECLAMC network (Latin American Collaborative Study on Congenital Malformations). From 1995 to 1999 in the ECLAMC member institutions $2,3.1 \%$ of newborns presented some type of congenital malformation.

In the attempt to obtain population-based information on malformations, beginning in January 2000, item number 34 was added to the Certificate of Live Birth in Brazil. This item records the detection of any congenital malformation and/or chromosomal anomaly and its type, according to the International Classification of Diseases (ICD-10) 3. Evaluating the reliability of the database on live births (SINASC) in the city of Rio de Janeiro from 1999 to 2001, the variable "presence of congenital anomaly" 
showed $11.7 \%$ lack of information, but excellent reliability (kappa index 0.97), with the patient medical chart as the source of data 4 .

Morbidity studies in children indicate that genetic diseases and congenital malformations represent $10-25 \%$ of hospitalizations in tertiary care facilities in some Latin America cities 5.

Childbearing-age women in developing countries like Brazil are exposed to potential teratogenic risks like infectious agents, environmental chemical compounds, radiation, use of medication, and maternal metabolic diseases 6 . These risk factors are highly relevant, since they interact with low schooling and low socioeconomic status in the population and scarce resources in the public health care system targeting the prevention and treatment of congenital anomalies 6 .

The current study aims to estimate the prevalence of congenital malformations at birth and the association with maternal schooling and other maternal characteristics, in addition to measuring the magnitude of malformations in relation to perinatal mortality.

\section{Material and methods}

The data used in this study are from the "Study of Perinatal and Neonatal Morbity and Mortality and Childbirth Care in the Municipality of Rio de Janeiro", conducted on the basis of a sample of postpartum women in maternity hospitals in Rio de Janeiro from July 1999 to March 2001.

Included in the study were 47 maternity hospitals aggregated in three sample strata: (1) 12 municipal and federal establishments; (2) 10 military, state, and charity establishments and those outsourced by the Unified National Health System (Sistema Único de Saúde - SUS); and (3) 25 private establishments. In each stratum, a sample was selected of approximately $10 \%$ of postpartum women from the number of births predicted for 1997 by SINASC/RJ. All the hospitals were included, except for those with fewer than 200 births per year, totaling 10,072 interviews.

The sample size in each stratum was determined so as to compare proportions in samples of equal sizes 7 at a $5 \%$ significance level and to detect differences of at least $3 \%$ with a test power of $90 \%$, based on the proportion of low birth weight $(<2,500 \mathrm{~g})$ according to the data for the city of Rio de Janeiro for the year 19978.

The pilot study was performed at an Academic Health Center and a University Maternity Hospital, the questionnaires from which were not included in the definitive database 9 .
Data collection for the study was done by scholarship students selected through an exam given by the Rio de Janeiro Municipal Health Department and who were trained and supervised by pediatricians. Three standardized questionnaires were used. The first was applied to mothers in the immediate postpartum, the second filled out with information from patient records, and the third with questions about the mother's and newborn's status at hospital discharge.

For quality control, field supervisors conducted a summary replication of the questionnaires in a $3 \%$ random sample of the interviews, in addition to duplicate keying-in of data from the questionnaires.

\section{Study variables}

Congenital anomaly was defined as a physical anatomical anomaly detected at birth and listed in Chapter XVII: Congenital Malformations, Deformations, and Chromosomal Abnormalities (Q00-Q99) of the International Classification of Diseases, 1997 (ICD-10) 3. This variable was obtained from the second questionnaire and was classified as a major or minor malformation based on its risk to the child's life and cosmetic significance 10 .

The available variables from the questionnaire were analyzed, related to maternal characteristics: skin color (based on the woman's self-classification); years of schooling; age bracket; parity; and number of prenatal visits; and characteristics of the maternity hospital: public or outsourced by the National Health system versus private; complexity (with or without neonatal ICU).

The following variables were selected to express the mother's lifestyle: attempt to terminate the index pregnancy; smoking during pregnancy; alcohol intake during the pregnancy; and illicit drug use during the pregnancy.

Maternal diseases evaluated were: arterial hypertension, diabetes mellitus, toxoplasmosis, syphilis, and rubella. Both for arterial hypertension and diabetes, preexisting diagnoses and those developed during the pregnancy were grouped together.

The following perinatal outcomes were obtained from the hospital discharge summary: prematurity ( $<37$ weeks gestational age, calculated from last menstrual period); low birth weight $(<2,500 \mathrm{~g})$; five-minute Apgar score less than seven; and perinatal death (death between 22 nd week of gestation and the seventh day postpartum). 


\section{Statistical analysis}

Prevalence of malformations was calculated in rates per ten thousand births according to the number of cases and non-cases of malformed children 2 .

Bivariate analyses were done for initial exploration of the data, using the chi-square and Fisher's exact test when necessary to test for homogeneity of proportions, comparing groups of births with and without congenital malformations at a 5\% significance level 11 .

Bivariate and multivariate logistic regression analyses were performed to verify the association between congenital malformation and the various risk factors. Crude odds ratios (OR) were obtained for all the variables. During this stage the perinatal outcomes were considered dependent variables. OR was used as an estimate of the prevalence rate, since the outcome is rare. Associations were considered statistically significant with $\mathrm{p} \leq 0.0511$.

The first multiple logistic regression model was used to estimate the effect of the maternal and health services variables on congenital malformation. In a second analysis, the model used perinatal death as the outcome, and all the variables were contemplated in this procedure, including congenital malformation and the perinatal outcomes. The automatic selection stepwise-forward procedure was used, based on goodness-of-fit, to calculate adjusted OR. Level of significance for inclusion of variables was set at $5 \%$ and for exclusion at $20 \%$.

In the multivariate modeling, some variables were grouped, like the number of prenatal visits ( 1.0 to 3 visits; 0.4 or more visits) and years of schooling ( 1 . up to 7 years; 0.8 or more years of schooling) or even disaggregated, as with maternal age, which considered the age extremes: younger than 20 years (1. up to 19 years; 0 . over 19 years) and maternal age greater than or equal to 35 years ( 1.35 years or older; 0 . up to 34 years).

The Hosmer-Lemeshow test was used to assess the model's fit. The strength of association between variables was expressed as adjusted OR with a 95\% confidence interval 12 .

The study was approved by the Institutional Review Board of the National School of Public Health, Oswaldo Cruz Foundation (Escola Nacional de Saúde Pública Sergio Arouca, Fundação Oswaldo Cruz). Each postpartum woman sampled to participate in the study, or her guardian in the case of minors, received a free informed consent form explaining the study's objectives and requesting written authorization.

\section{Results}

In the three strata, a total of 10,072 interviews were performed, with an overall loss of $4.5 \%$. Losses were higher $(9.3 \%)$ in stratum three, which included the private maternity hospitals. The principal reason for losses was the mother's refusal to participate in the study 9. From this initial sample, 686 subjects were excluded whose information on congenital malformation was unknown or was not on the ICD-10 list.

The universe for this study thus became 9,386 births, with 162 cases (1.7\%) of congenital malformations distributed as follows: 137 newborns presented a single type of malformation; 11, two malformations; and one with three malformations. $56.5 \%$ were male and $42.9 \%$ female, with one newborn of indeterminate sex.

Minor malformations represented $66 \%$ of the total detected in this sample. Defects of limbs/extremities (polydactyly, congenital clubfoot) and skin (congenital non-neoplastic nevus) were the principal minor anomalies identified.

The most frequent site of major malformations was the central nervous system: seven cases of spina bifida, five of hydrocephalus, three of encephalocele, and one each of anencephaly and microcephaly. Other important sites and systems included the face (cleft lip and/or palate) and abdominal wall (gastroschisis and omphalocele), with 10 and 7 cases, respectively. The only chromosomal anomaly diagnosed in this study was Down syndrome (Table 1).

As shown in Table 2, prevalence of congenital malformations was higher in African-descendant and Asian-descendent, adolescent, and primiparous mothers, but the difference was not statistically significant. The variable "years of schooling" shows a higher rate of congenital anomalies among mothers with less schooling. Odds of congenital anomaly in this group were $22 \%$ greater $(\mathrm{OR}=1.22 ; 95 \% \mathrm{CI}$ : 1.01-1.46) as compared to the group with more schooling.

As for use of health services, children born in public maternity hospitals or those outsourced by the SUS had a higher proportion of congenital malformations than those born in private maternity hospitals. Prenatal care was a protective variable, since there was a lower prevalence of anomalies with more adequate prenatal care.

The environmental variables "attempt to terminate the pregnancy", "smoking during pregnancy", "illicit drug use during the pregnancy", "history of diabetes", and "toxoplasmosis during the pregnancy" showed a positive as- 
Distribution of congenital malformations according to major and minor ICD-10 types and prevalence rates per 10 thousand births. Municipality of Rio de Janeiro, Brazil, 1999-2001.

\begin{tabular}{|c|c|c|c|c|}
\hline Type of malformation & ICD-10 & $\mathbf{n}$ & $\%$ & Rate \\
\hline \multicolumn{5}{|l|}{ Major malformations } \\
\hline Spina bifida & Q05 & 7 & 4.32 & 7.46 \\
\hline Down syndrome, unspecified & Q90 & 6 & 3.70 & 6.39 \\
\hline Hydrocephalus & Q03 & 5 & 3.09 & 5.33 \\
\hline Gastroschisis & Q79.3 & 5 & 3.09 & 5.33 \\
\hline Cleft palate & Q35 & 4 & 2.47 & 4.26 \\
\hline Imperforate anus & Q42.3 & 4 & 2.47 & 4.26 \\
\hline Cleft lift with cleft palate & Q37 & 4 & 2.47 & 4.26 \\
\hline Encephalocele & Q01 & 3 & 1.85 & 3.20 \\
\hline Congenital diaphragmatic hernia & Q79.0 & 3 & 1.85 & 3.20 \\
\hline Cleft lip & Q36 & 2 & 1.23 & 2.13 \\
\hline Omphalocele & Q79.2 & 2 & 1.23 & 2.13 \\
\hline Anencephaly & Q00 & 1 & 0.62 & 1.07 \\
\hline Microcephaly & Q02 & 1 & 0.62 & 1.07 \\
\hline Congenital heart block & Q24.6 & 1 & 0.62 & 1.07 \\
\hline Conjoined twins & Q89.4 & 1 & 0.62 & 1.07 \\
\hline Multiple malformations & Q89.7 & 1 & 0.62 & 1.07 \\
\hline Subtotal & - & 55 & 33.95 & 58.60 \\
\hline \multicolumn{5}{|l|}{ Minor malformations } \\
\hline Polydactyly & Q69 & 23 & 14.20 & 24.50 \\
\hline Congenital clubfoot & Q66.0 & 15 & 9.26 & 15.98 \\
\hline Congenital non-neoplastic nevus & Q82.5 & 13 & 8.02 & 13.85 \\
\hline Hypospadia & Q54 & 8 & 4.94 & 8.52 \\
\hline Congenital malformation of the hip & Q65 & 5 & 3.09 & 5.33 \\
\hline Syndactyly & Q70 & 4 & 2.47 & 4.26 \\
\hline Choanal atresia & Q30.0 & 4 & 2.47 & 4.26 \\
\hline Epispadia & Q64.0 & 1 & 0.62 & 1.07 \\
\hline Misplaced/low-set ears & Q17.4 & 1 & 0.62 & 1.07 \\
\hline Single umbilical artery & Q27.0 & 1 & 0.62 & 1.07 \\
\hline Subtotal & - & 107 & 66.05 & 114.00 \\
\hline
\end{tabular}

sociation with congenital malformations, but without statistical significance. There was no case of malformation in newborns of mothers who reported rubella during the pregnancy.

Caution should be used in analyzing the variables: yellow skin color (sic, i.e., Asian descent), drug use during pregnancy, and presence of syphilis or toxoplasmosis during the pregnancy, since each presented a very limited number of few cases.

When analyzing the perinatal outcomes (Table 3) according to the presence of congenital malformation, all of the variables showed higher proportions in the group of children with malformations, and perinatal mortality was seven times greater ( $5.4 \%$ versus $0.7 \%$ ) among children with malformations. Since in this stage of the analysis congenital malformation was considered an independent variable, there was more than double the rate of low birth weight among infants with congenital malformations $(\mathrm{OR}=2.42$; 95\%CI: 1.60-3.68) and nearly double the rate of prematurity $(\mathrm{OR}=1.82 ; 95 \% \mathrm{CI}$ : 1.19-2.77); in addition, the five-minute Apgar of less than 7 was significantly more common among infants with congenital malformations $(\mathrm{OR}=3.75$; 95\%CI: 2.05-6.90). The odds of perinatal death were more than eight times greater among those with congenital malformations $(\mathrm{OR}=8.40 ; 95 \% \mathrm{CI}: 3.95-17.86)$, as compared to newborns without malformations.

Table 4 shows the result of multiple logistic regression analysis with congenital malformation as the outcome. Of the set of explanatory 
Proportional distribution of some factors linked to maternal and health services characteristics according to presence of congenital malformations, and corresponding crude odds ratios (OR). Municipality of Rio de Janeiro, Brazil, 1999-2001.

\begin{tabular}{|c|c|c|c|c|c|c|}
\hline \multirow[t]{3}{*}{ Variables } & \multicolumn{4}{|c|}{ Presence of malformations } & \multirow[t]{3}{*}{$\mathrm{OR}_{\text {crude }}(95 \% \mathrm{Cl})$} & \multirow[t]{3}{*}{$p$ value ${ }^{x}$} \\
\hline & \multicolumn{2}{|c|}{ Yes } & \multicolumn{2}{|c|}{ No } & & \\
\hline & $\mathrm{n}$ & $\%$ & $\mathrm{n}$ & $\%$ & & \\
\hline \multicolumn{7}{|l|}{ Social and reproductive factors } \\
\hline Skin color & & & & & & 0.319 \\
\hline White & 66 & 1.4 & 4,690 & 98.6 & 1.00 & \\
\hline Black or brown & 77 & 1.8 & 4,276 & 98.2 & $1.25(0.93-1.68)$ & \\
\hline Yellow & 4 & 1.9 & 205 & 98.1 & $1.13(0.96-1.33)$ & \\
\hline Years of schooling & & & & & & 0.010 \\
\hline$\leq 7$ & 77 & 2.1 & 3,676 & 97.9 & $1.22(1.01-1.46)$ & \\
\hline $8-10$ & 24 & 1.1 & 2,137 & 98.9 & $0.79(0.48-1.30)$ & \\
\hline 11 or more & 48 & 1.4 & 3.397 & 98.6 & 1.00 & \\
\hline Maternal age bracket (years) & & & & & & 0.161 \\
\hline$\leq 19$ & 38 & 2.1 & 1,786 & 97.9 & $1.41(0.96-2.05)$ & \\
\hline $20-34$ & 96 & 1.5 & 6,350 & 98.5 & 1.00 & \\
\hline 35 or more & 15 & 1.4 & 1,094 & 98.6 & $0.95(0.72-1.25)$ & \\
\hline Previous children & & & & & & 0.159 \\
\hline None & 69 & 1.8 & 3,748 & 98.2 & 1.00 & \\
\hline 1 or more & 80 & 1.4 & 5,484 & 98.6 & $0.79(0.57-1.09)$ & \\
\hline \multicolumn{7}{|l|}{ Health services } \\
\hline Prenatal visits & & & & & & 0.001 \\
\hline $0-3$ & 20 & 3.2 & 610 & 96.8 & $1.57(1.22-2.01)$ & \\
\hline $4-6$ & 48 & 1.9 & 2,506 & 98.1 & $1.44(1.00-2.07)$ & \\
\hline 7 or more & 75 & 1.3 & 5,642 & 98.7 & 1.00 & \\
\hline Type of Maternity Hospital & & & & & & 0.000 \\
\hline Private & 25 & 0.9 & 2,909 & 99.1 & 1.00 & \\
\hline Affiliated with NHS & 124 & 1.9 & 6,328 & 98.1 & $2.28(1.48-3.51)$ & \\
\hline Complexity of maternity hospital & & & & & & 0.337 \\
\hline Without neonatal ICU & 75 & 1.7 & 4,284 & 98.3 & 1.00 & \\
\hline With neonatal ICU & 74 & 1.5 & 4,953 & 98.5 & $0.85(0.62-1.18)$ & \\
\hline \multicolumn{7}{|l|}{ Environmental factors } \\
\hline Attempted to terminate pregnancy & 11 & 2.2 & 486 & 97.8 & $1.43(0.77-2.66)$ & 0.256 \\
\hline No & 138 & 1.6 & 8,724 & 98.4 & & \\
\hline Smoking during pregnancy & 22 & 1.8 & 1,208 & 98.2 & $1.15(0.73-1.81)$ & 0.550 \\
\hline No & 127 & 1.6 & 8,015 & 98.4 & & \\
\hline Alcohol consumption during pregnancy & 20 & 1.1 & 1,773 & 98.9 & $0.65(0.40-1.05)$ & 0.074 \\
\hline No & 129 & 1.7 & 7,447 & 98.3 & & \\
\hline Illicit drug use during pregnancy & 2 & 5.0 & 38 & 95.0 & $3.28(0.78-13.73)$ & 0.085 \\
\hline No & 147 & 1.6 & 9,169 & 98.4 & & \\
\hline \multicolumn{7}{|l|}{ Clinical factors } \\
\hline Arterial hypertension & 14 & 1.5 & 917 & 98.5 & $0.95(0.54-1.65)$ & 0.846 \\
\hline No & 133 & 1.6 & 8,246 & 98.4 & & \\
\hline Diabetes mellitus & 5 & 3.2 & 152 & 96.8 & $2.07(0.83-5.11)$ & 0.109 \\
\hline No & 143 & 1.6 & 8,980 & 98.4 & & \\
\hline Syphilis & 1 & 0.7 & 142 & 99.3 & $0.44(0.61-3.15)$ & 0.340 \\
\hline No & 141 & 1.6 & 8,770 & 98.4 & & \\
\hline Toxoplasmosis & 2 & 4.2 & 46 & 95.8 & $2.79(0.67-11.60)$ & 0.170 \\
\hline No & 136 & 1.5 & 8,721 & 98.5 & & \\
\hline
\end{tabular}

* Chi-square test. 
Proportion of congenital malformations according to perinatal outcomes, and corresponding crude odds ratios (OR). Municipality of Rio de Janeiro, Brazil, 1999-2001.

\begin{tabular}{|c|c|c|c|c|c|c|}
\hline \multirow[t]{3}{*}{ Variables } & \multicolumn{4}{|c|}{ Presence of malformation } & \multirow[t]{3}{*}{ OR $_{\text {crude }}(95 \% \mathrm{Cl})$} & \multirow[t]{3}{*}{ p value* } \\
\hline & \multicolumn{2}{|c|}{ Yes } & \multicolumn{2}{|c|}{ No } & & \\
\hline & $\mathrm{n}$ & $\%$ & $\mathrm{n}$ & $\%$ & & \\
\hline \multicolumn{7}{|l|}{ Perinatal outcomes } \\
\hline Low birth weight $(<2,500 \mathrm{~g})$ & & & & & & 0.000 \\
\hline Yes & 28 & 18.8 & 799 & 8.7 & $2.42(1.60-3.68)$ & \\
\hline No & 121 & 81.2 & 8,376 & 91.3 & & \\
\hline Prematurity (< 37 weeks gestation) & & & & & & 0.005 \\
\hline Yes & 27 & 18.9 & 1,002 & 11.4 & $1.82(1.19-2.77)$ & \\
\hline No & 116 & 81.1 & 7,813 & 88.6 & & \\
\hline 5-minute Apgar $<7$ & & & & & & 0.000 \\
\hline Yes & 12 & 8.6 & 209 & 2.4 & $3.75(2.05-6.90)$ & \\
\hline No & 128 & 91.4 & 8,376 & 97.6 & & \\
\hline Perinatal death & & & & & & 0.000 \\
\hline Yes & 8 & 5.4 & 62 & 0.7 & $8.40(3.95-17.86)$ & \\
\hline No & 141 & 94.6 & 9,175 & 99.3 & & \\
\hline
\end{tabular}

* Chi-square test.

variables, only four were selected for inclusion in the model based on the established statistical criteria. An insufficient number of prenatal visits $(\leq 3)$ showed twice the probability $(\mathrm{AOR}=$ 2.16) of malformation compared to mothers with more than 4 visits. The occurrence of malformation showed odds of 2.13 among infants born in maternity hospitals affiliated with the SUS as compared to private maternity hospitals and 2.45 in the presence of maternal diabetes, although without statistical significance. In addition, a history of one or more previous children was a protective factor in relation to congenital malformation.

According to the second logistic regression model (Table 5), a five-minute Apgar score of less than 7, congenital malformation, low birth weight, and prematurity were relevant factors for explaining perinatal death.

\section{Discussion}

The $1.7 \%$ prevalence rate for congenital malformation in this sample of births in the city of Rio de Janeiro was less than observed in various other studies to monitor birth defects, which varied from $2.7 \% 2$ to $4.7 \% 13$. This difference was probably due primarily to the database, since hospital-based studies often use reference hospitals for neonatal risk and thus tend to overestimate the prevalence. The method- ological characteristics of the various studies can also have an impact, given that the use of patient files as the source of data collection may have been a limitation.

In studies that combine major and minor malformations, the latter are more frequent and the prevalence rates for clubfoot and hypospadia were equivalent to those of the ECLAMC 4 , 16.4 and 8.5 per 10 thousand births, respectively.

Cases of major malformations occur predominantly in the central nervous system, especially neural tube defects (spina bifida, anencephaly, and encephalocele). These defects are amenable to prevention with the use of folic acid during the period surrounding conception, i.e., for at least one month prior to conception until the end of the first trimester of pregnancy. Since this would tend to only benefit women who plan their pregnancies, some countries like Australia (1995), United States (1996), Canada (1998), and Chile (2000) have adopted wheat flour fortification with folic acid as a more efficient means of reaching a higher proportion of childbearing-age women 14 . This strategy has proven effective for decreasing the prevalence of neural tube defects by $50 \%$ in Canada 15 and $31 \%$ in Chile 16. In Brazil, fortification of wheat and corn flour with folic acid has been mandatory since June 200417.

The low prevalence of cardiovascular defects at birth is considered consistent with the literature, given that their diagnosis is usually 
performed later, after discharge from the maternity hospital, in addition to depending on advance diagnosis during prenatal care.

Of the maternal characteristics studied here, low schooling was associated with congenital malformation in the bivariate regression. Considering schooling as a proxy for socioeconomic status, these results corroborate those of Schuler-Faccini et al. 6, who indicated that lowincome women show more risk factors for birth defects.

Advanced maternal age ( $>35$ years) has been the most frequently reported risk factor for birth defects in Brazil, especially for chromosomal anomalies like Down syndrome, which occurs more frequently with increasing maternal age 18 . The current birth sample did not show any association between maternal age and malformation, a result similar to that of a study in Chile by Pardo et al. 19, where the proportion of malformations did not differ significantly between adolescent as compared to older mothers. Neither was an age-related difference observed in mothers of children with neural tube defects in a study at the maternity ward of the Federal University Hospital in the State of Minas Gerais 20.

Lifestyle factors have drawn increasing attention due to their capacity to influence the result of conception 18 . Smoking has been associated with cleft lip 22 , and alcohol use with fetal alcohol syndrome 18. The current sample did not show a significant difference in smoking or alcohol consumption during pregnancy when comparing mothers of newborns with or without a diagnosis of congenital malformation. Some hypotheses can be raised, including the possibility that mothers of newborns with birth defects may attempt to protect themselves by denying or underestimating their risk behaviors during pregnancy, including alcohol consumption and cigarette smoking. Another hypothesis relates to the way such variables have been analyzed, without taking into account the number of cigarettes smoked or the actual amount of alcohol consumed.

Multiple logistic regression analysis to determine the variables with the greatest association with congenital malformations showed results that have been recognized in the scientific literature. The importance of prenatal care for a healthy birth outcome is widely recognized, decreasing the risk of low birth weight, prematurity, and infant death 22 . Analysis of the current data shows increased odds of birth defects among newborns of mothers with few or no prenatal visits during the index gestation. This association remains in the model even af-
Table 4

Results of multiple logistic regression with congenital malformation as the outcome variable. Municipality of Rio de Janeiro, Brazil, 1999-2001.

\begin{tabular}{lccc}
\hline Variables & AOR & $\mathbf{9 5 \% C l}$ & p value \\
\hline Presence of diabetes mellitus & 2.45 & $0.98-6.12$ & 0.06 \\
$\leq 3$ prenatal visits & 2.16 & $1.29-3.64$ & 0.00 \\
Maternity hospital (public or & 2.13 & $1.35-3.37$ & 0.00 \\
outsourced by NHS) & & & \\
One or more previous children & 0.64 & $0.44-091$ & 0.01 \\
\hline
\end{tabular}

Hosmer \& Lemeshow ( $p$ value $=0.95) 12$.

Table 5

Results of multiple logistic regression with perinatal death as the outcome variable. Municipality of Rio de Janeiro, Brazil, 1999-2001.

\begin{tabular}{lrcc}
\hline Variable & AOR & $\mathbf{9 5 \% C l}$ & p value \\
\hline Low birth weight & 8.78 & $2.76-27.91$ & 0.00 \\
Prematurity & 5.33 & $1.66-17.09$ & 0.00 \\
5-minute Apgar $<7$ & 23.13 & $10.18-52.53$ & 0.00 \\
Congenital malformation & 8.47 & $2.41-29.82$ & 0.00 \\
\hline
\end{tabular}

Hosmer \& Lemeshow (p-value $=0.33)^{12}$.

ter controlling for the other variables. According to Carmichael et al. 24, the risk of malformation was 1.50 for women who began their prenatal care later in pregnancy, acting as an indicator of adverse social factors such as skin color, parity, age, deficient health care, and exposure to gestational risk factors like smoking and alcohol consumption.

The proportion of congenital malformations in infants born in public maternity hospitals or those outsourced by the National Health System was significantly greater than among infants born in private maternity hospitals. Nazer et al. 24 also found a higher prevalence of neural tube defects in public maternity hospitals in Chile. Public maternity hospitals may reflect care for mothers with lower socioeconomic status, whose access to nutrients is lower, thus increasing the probability of developing structural abnormalities. On the other hand, the lower prevalence of congenital malformations in private maternity hospitals may reflect behavior by women with higher socioeconomic status (similar to those from developed countries), due either to greater self-care and care for the infant or termination of the pregnancy 
following intrauterine diagnosis of a fetal malformation 25 .

Certain maternal diseases may occasionally lead to increased risk of birth defects. According to Ordonez et al. 26, diabetes mellitus, arterial hypertension, and hypothyroidism show a positive association with congenital malformation. In the current birth sample, diabetes mellitus was the only maternal disease positively associated with birth defects. According to Castilla et al. 18, this disease accounts for the induction of diabetic embryopathy, resulting in malformations and spontaneous abortions, especially in the first trimester of pregnancy.

Previous studies have shown conflicting results in relation to parity as a variable. Aguiar et al. 20 found a lower risk of neural tube defect in children of multiparous women, while Castilla et al. 18 found a higher risk with greater parity (three or more children). In our study, women with one or more previous children had a $37 \%$ lower risk of newborns with malformations as compared to women giving birth for the first time, after controlling for the other variables in the model.

The results indicate an increased frequency of low birth weight, prematurity, and anoxia among newborns with malformations, emphasizing the fact that these children require highcomplexity care at birth, thus justifying the need for reference units for such cases.

In relation to birth weight, according to reports in the literature, children with neural tube defects show an increased proportion of low birth weight 19,20,24 due to the malformations themselves, as in anencephaly, or as the result of their effect on fetal growth. Another explanatory hypothesis is that children with adverse outcomes require intensive care in the first days of life and in some cases admission to an intensive care unit, thereby increasing the probability of diagnosing an anomaly.

Congenital malformations have gained increasing importance due both to mortality and morbidity. According to Chung \& Myrianthopoulos 10 , the odds of a child with a congenital malformation dying were 3.85 in the neonatal period and 2.81 in the post-neonatal period. In this study, congenital malformations $(\mathrm{AOR}=8.47$ ) showed the same magnitude in determining perinatal death as did low birth weight $(\mathrm{AOR}=$ 8.78).

Some children require immediate surgical treatment to increase their odds of survival, and many need prolonged rehabilitation, sometimes for their entire lives. This study highlights the importance of prenatal care as a preventive factor against congenital malformations and perinatal death.

The current study contributes to the planning of measures in maternal and child health, with a focus on resource allocation for prevention of congenital malformations, both primary (health education), secondary (adequate prenatal care with broad coverage), and tertiary (organization of referral networks).

A limitation of the current study is the sample size together with the low prevalence of the target outcome, leading to wide confidence intervals. However, due to the importance of this outcome and the lack of information on the theme in Brazil, we felt it was pertinent to analyze the issue, in the belief that we would contribute to the understanding of the prevalence and distribution of congenital malformations in our city.

\section{Resumo}

Este trabalho tem como objetivo estimar a prevalência ao nascimento das malformações congênitas e sua associação com escolaridade e outras características maternas. Trata-se de um estudo seccional, a partir de uma amostra de 9.386 puérperas hospitalizadas em maternidades do Município do Rio de Janeiro, Brasil, no momento do parto, no período de 1999 a 2001. Os dados foram coletados através de entrevistas com as mães, no pós-parto imediato, assim como consulta aos prontuários das puérperas e dos recém-nascidos. A prevalência ao nascimento de malformação congênita foi de 1,7\% e as malformações menores foram as mais freqüentes (polidactilia e pé torto congênito). Os defeitos de fechamento do tubo neural foram as princi-

pais anomalias maiores detectadas. Na análise multivariada, a anomalia congênita esteve associada à maternidade ser pública ou conveniada com o SUS e receber inadequada assistência pré-natal (até três consultas). Ressalta-se neste estudo a importância de ações de promoção da saúde e prevenção de agravos a mulheres em idade fértil, com atenção especial para o atendimento ao pré-natal e ao parto, que podem repercutir diretamente nos indicadores infantis e na prevenção das anomalias congênitas.

Defeitos Congênitos; Recém-nascido; Prevalência; Fatores de Risco 


\section{Contributors}

C. M. S. Costa conducted the literature review, built the database, conducted the data analysis and interpretation, and was mainly responsible for writing the article. S. G. N. Gama participated in defining the method- ology and contributed to the analysis and interpretation of the results and writing of the article. M. C. Leal participated in the definition of the methodology, discussion of the results, and final revision of the article.

\section{References}

1. Secretaria de Estado de Saúde do Rio de Janeiro. Indicadores e informações em saúde. http:// www.saude.rj.gov.br/informcoes/obitos.shtml (accessed on 24/Aug/2005).

2. Nazer J, Aravena T, Cifuentes L. Malformaciones congénitas en Chile. Un problema emergente (período 1995-1999). Rev Med Chile 2001; 129:895904.

3. Organização Mundial da Saúde. Classificação estatística internacional de doenças e problemas relacionados à saúde, 10a Revisão. v. 1. São Paulo: Centro Colaborador da OMS para a Classificação de Doenças em Português; 1995.

4. Theme Filha MM, Gama SGN, Cunha CB, Leal MC. Confiabilidade do Sistema de Informações sobre Nascidos Vivos hospitalares no Município do Rio de Janeiro, 1999-2001. Cad Saúde Pública 2004; 20 Suppl 1:S83-91.

5. Cunha AJB. Orientação genética-clínica em medicina fetal. In: Isfer EV, Sanchez RC, Saito M, organizadores. Medicina fetal diagnóstico pré-natal e conduta. Rio de Janeiro: Revinter; 1996. p. 1-19.

6. Schuler-Faccini L, Leite JCL, Sanserino MTV, Peres RM. Avaliação de teratógenos na população brasileira. Ciênc Saúde Coletiva 2002; 7:66-71.

7. Fleiss JL. Statistical methods for rates and proportions. 2nd Ed. New York: John Wiley \& Sons; 1981.

8. Leal MC, Gama SGN, Campos MR, Cavalini LT, Garbayo LS, Brasil CLP, et al. Fatores associados à morbi-mortalidade perinatal em uma amostra de maternidades públicas e privadas do Município do Rio de Janeiro, 1999-2001. Cad Saúde Pública 2004; 20 Suppl 1:S20-33.

9. Campos MR, Leal MC, Souza Jr. PR, Cunha CB. Consistência entre fontes de dados e confiabilidade interobservador do Estudo da Morbi-mortalidade e Atenção Peri e Neonatal no Município do Rio de Janeiro. Cad Saúde Pública 2004; 20 Suppl 1:S34-43.

10. Chung CS, Myrianthopoulos NC. Congenital anomalies: mortality and morbidity, burden and classification. Am J Medical Genetics 1987; 27:505-23.

11. Menezes RX. Teste para médias. In: Massad E, Menezes RX, Silveira PSP, Ortega NRS, organizadores. Métodos quantitativos em medicina. Barueri: Editora Manole; 2004. p. 243-75.

12. Hosmer DW, Lemeshow S. Applied logistic regression. New York: John Wiley \& Sons; 2000.

13. Moreira LMA, Dias AL, Ribeiro HBS, Falcão CL, Felício TD, Stringuetti C, et al. Associação entre o uso de abortifacientes e defeitos congênitos. Rev Bras Ginecol Obstet 2001; 23:517-51.

14. Cornel MC, Erickson JD. Comparison of national policies on periconceptional use of folic acid to prevent spina bifida and anencephaly (SBA). Teratology 1997; 55:134-7.

15. Ray JG, Meier C, Vermeulen MJ, Boss S, Wyatt PR, Cole DEC. Association of neural tube defects and folic acid food fortification in Canada. Lancet 2002; 360:2047-8.

16. Castilla EE, Orioli IM, Lopez-Camelo JS, Dutra MG, Nazer-Herrera J. Preliminary data on chances in neural tube defect prevalence rates after folic acid fortification in South America. Am J Med Genet A 2003; 123:123-8.

17. Resolução RDC n. 344, de 13 de dezembro de 2002. http://www.anvisa.gov.br/legis/resol/2002/ 344_02rdc.htm. (accessed on 23/Nov/2004).

18. Castilla EE, Lopez-Camelo JS, Paz JE, Orioli IM. Prevención primaria de los defectos congénitos. Rio de Janeiro: Editora Fiocruz; 1996.

19. Pardo RA, Nazer J, Cifuentes L. Prevalencia al nacimiento de malformaciones congénitas y de menor peso de nacimiento en hijos de madres adolescentes. Rev Med Chile 2003; 131:1165-72.

20. Aguiar MJB, Campos AS, Aguiar RALP, Lana AMA, Magalhães RL, Babeto LT. Defeitos de fechamento do tubo neural e fatores associados em recémnascidos vivos e natimortos. J Pediatr (Rio J) 2003; 79:129-34.

21. van Rooij IALM, Groenen PMW, van Drongelen M, Te Morsche RHM, Peters WHM, Steegers-Theunissen RPM. Orofacial clefts and spina bifida: Nacetyltransferase phenotype, maternal smoking, and medication use. Teratology 2002; 66:260-6.

22. Secretaria de Políticas de Saúde, Ministério da Saúde. Manual técnico gestação de alto risco. 3a Ed. Brasília: Ministério da Saúde; 2000.

23. Carmichael SL, Shaw GM, Nelson V. Timing of prenatal care initiation and risk of congenital malformations. Teratology 2002; 66:326-30.

24. Nazer J, López-Camelo J, Castilla EE. ECLAMC: Estudio de 30 años de vigilancia epidemiológica de defectos de tubo neural en Chile y en Latinoamérica. Rev Med Chile 2001; 129:531-9.

25. Liu S, Joseph KS, Wen SW, Kramer MS, Marcoux S, Ohlsson A, et al. Secular Trends in Congenital Anomaly-Related Fetal and Infant Mortality in Canada, 1985-1996. Am J Med Genet 2001; 104:713.

26. Ordonez A MP, Nazer HJ, Aguila RA, Cifuente LO. Malformaciones congénitas y patología crónica de la madre. Estudio ECLAMC 1971-1999. Rev Med Chile 2003; 131:404-11.

Submitted on $17 /$ Jan/2005

Final version resubmitted on 26/Aug/2005

Approved on 27/Sep/2005 